\title{
Megarectum in constipation
}

R N van der Plas, M A Benninga, C R Staalman, L M A Akkermans, W K Redekop, J A Taminiau, H A Büller

\begin{abstract}
Background-Faecal impaction is frequently observed in children with chronic constipation. The term megarectum is often used to describe this finding.

Aim-To evaluate rectal functioning and rectal measures in constipated children with a filled rectum, in order to define the terms faecal impaction, enlarged rectum, and megarectum.
\end{abstract}

Methods-All children underwent radiological investigation, colonic transit time study, anorectal manometry, and rectal volume and rectal wall compliance measurements. Patients with faecal impaction were compared with controls, who had an empty rectum on digital rectal examination.

Results-A total of 31 patients and six controls were included in the study. The mean duration of complaints was 4.2 years and all had faecal incontinence. The colonic transit times in the patients showed a distinct delay in the rectosigmoid segment. Anorectal manometry was not significantly different between patients and controls. The rectal width in patients was 0.68 and in controls 0.52 with an upper limit of 0.61 . The pressurevolume curve in patients showed significant less relaxation at a distension of $\mathbf{5 0}$ $\mathrm{ml}$. The slope of the curve (corresponding with rectal wall compliance) was comparable for patients and controls.

Conclusions-We suggest that faecal impaction is a filled rectum found on digital rectal examination; an enlarged rectum is defined by a rectopelvic ratio greater than 0.61 ; and megarectum is defined in those with significant abnormalities found with anorectal manometry, pressure-volume curves, or rectal compliance investigation. A diminished relaxation of the rectum on rectal distension could be the first sign of megarectum in children with chronic constipation.

(Arch Dis Child 2000;83:52-58)

Keywords: megarectum; constipation; faecal incontinence

In children with Hirschsprung's disease, meningomyelocele, or anal atresia, there is consensus about the meaning of the term megarectum. ${ }^{1}$ It means a large filled rectum as a result of underlying nerve supply abnormalities or muscle dysfunction, which remains after disimpaction of the rectum. In patients with constipation, the term megarectum is often used indiscriminately. For some it means a large rectal mass on rectal examination, while for others it means a wide rectum on an abdominal $x$ ray, the presence of impaired rectal sensation, or the finding of large maximal rectal volumes on anorectal manometry. ${ }^{2-6}$ This has resulted in a wide range of reported prevalence for megarectum in constipated patients, varying from $29 \%$ to $100 \% .^{157-12}$ In adults, Preston et al defined megarectum by a bowel width of $6.5 \mathrm{~cm}$ at the pelvic brim on a lateral $x$ ray of the abdomen. ${ }^{13}$ In children, only one study has reported an objective measure of the size of the rectum: the recto-pelvic ratio (RPR). However, clear cut off points to define an abnormal size of the rectum were not given. ${ }^{514} 15$ Thus, there is no uniform definition of megarectum for patients with constipation. It is unknown whether a large rectum is the result or the cause of constipation, and which underlying mechanism is responsible for faecal impaction. ${ }^{516}$ Some investigators have suggested that the nerve plexuses and smooth muscle coats in children with faecal impaction are normal. ${ }^{5}$ 17-19

The symptoms related to faecal impaction are a decreased defaecation frequency, passing massive stools, abdominal pain, abdominal distension, and overflow incontinence. ${ }^{2} 15$ 17 19-23 Other studies in children with constipation showed relations between night time soiling and paediatric slow transit constipation, and between faecal overflow incontinence and the presence of rectal faecal impaction. ${ }^{15}{ }^{24}$ The large variation of symptoms and the possible different mechanisms make it important to achieve consensus about the terms faecal impaction, enlarged rectum, and megarectum. We conducted a controlled study in constipated children with faecal impaction and children with abdominal pain but without faecal impaction as diagnosed by rectal digital examination, in order to evaluate rectal measurements and function, and to define terminology.

\section{Methods}

Children with chronic constipation were referred by paediatricians and general practitioners to the paediatric motility unit of the Academic Medical Centre in Amsterdam, the Netherlands. Patients were selected on the basis of constipation when they met at least two of the following criteria: (1) defaecation frequency less than three times per week; (2) soiling and/or encopresis more than two times per week; (3) production of large amounts of stool once per 7-30 days; and (4) the presence of a palpable abdominal or rectal mass. ${ }^{25}$ All patients had a palpable abdominal or rectal mass (either a large massive faecal lump or a large amount of soft stool that filled the rectal ampul) on physical examination. ${ }^{8}$ Soiling was defined as the loss of a small amount of loose 
stool in the underwear. Encopresis was defined as the loss of a normal amount of stool in the underwear after the age of 4 years, without an underlying organic disorder.

The control group comprised six children with recurrent abdominal pain and without rectal faecal impaction. They were included on the basis of the definition of chronic abdominal pain as defined by Apley and Naish. ${ }^{26}$ All controls passed at least one normal stool every two days and they did not meet the criteria for paediatric constipation as defined above. ${ }^{5}$ All controls underwent rectometrography with barium and anorectal manometry. None of the patients or controls had Hirschsprung's disease.

Written informed consent was obtained from the parents of the children and cooperation was obtained from each child. The protocol was approved by the medical ethics committee of the hospital. Figure 1 shows the time schedule in which the investigations were performed.

\section{MEDICAL HISTORY}

The child and parents were interviewed to provide the following information: duration of defaecation problems, defaecation frequency, soiling and/or encopresis frequency, consistency and size of stool, pain during defaecation, and associated symptoms such as abdominal pain, appetite, and enuresis.

PHYSICAL EXAMINATION

Abdominal examination focused on the presence of distension and palpable faecal masses. Digital rectal examination provided information about anal tone and the presence of rectal faecal impaction.

Subsequent anorectal investigations were performed. The colonic transit time and the RPR were measured when the rectum was fullthat is, before a disimpaction programme. The following investigations were performed with an empty rectum: balloon-pelvic ratio (BPR), sensory threshold, rectometrography, and anorectal manometry.

COLONIC TRANSIT TIME

Total and segmental colonic transit time (CTT) studies were assessed using previously described methods. ${ }^{72}$ The studies were done before the rectal disimpaction programme and patients discontinued laxatives for at least four days before the investigation was started. They ingested one capsule with 24 identical radioopaque markers on three consecutive days. Abdominal radiographs were obtained at day 1 and day 4 after ingestion of the last capsule. If more than $20 \%$ of the markers were still visible on the $x$ ray picture, an additional abdominal radiograph was performed after another three days. Localisation of markers depended on the

$\mathrm{I} \rightarrow(>3$ days $) \rightarrow \mathrm{II} \rightarrow(1$ week $) \rightarrow$ II $\rightarrow(1$ week $) \rightarrow$ IV

Figure 1 Time schedule of investigations. I: first visit: medical history and physical examination, followed a period of at least four days without laxatives. II: colonic transit time measurement and measurement of the recto-pelvic ratio at day 4 after ingestion of the last capsule with radio-opaque markers (total duration one week). III: rectal disimpaction programme with enemas and oral laxatives during approximately one week. IV: abdominal $x$ ray with barium and measurement of the balloon-pelvic ratio, rectometrography, and anorectal manometry. (Total investigation time: two weeks and four days.) identification of bony landmarks on the abdominal $x$ ray picture. ${ }^{28}$ Markers were counted in the right, left, and rectosigmoid regions. Segmental and total colonic transit times were calculated according to a previously described formula. ${ }^{27}{ }^{28}$ Owing to the need to limit radiological investigations colonic transit time and rectal width measurement were not performed in the control group.

RECTAL WIDTH

The rectal width was measured at the time of the second $x$ ray examination, performed for CTT measurement, in order to obtain standard conditions in all patients. Prior to the second $x$ ray examination, a total of $10 \mathrm{ml}$ of diluted barium suspension ( $5 \mathrm{ml}$ barium in 40 $\mathrm{ml}$ of water) was introduced in the rectum. This was done to avoid misinterpretation of rectal size because of overlap with the sigmoid, to appropriately delineate the size of the faecal mass, and to differentiate faecal mass from the rectal wall. The size of the faecal mass was expressed by the RPR. The RPR was obtained by dividing the diameter of the rectal width by the diameter of the linea transversa of the pelvis (fig 2). This method provides objective and reproducible values for the size of the rectum. ${ }^{5}$

\section{DISIMPACTION PROGRAMME}

All patients subsequently underwent an outpatient rectal disimpaction programme using enemas ( $120 \mathrm{ml}$ sodium dioctylsulphosuccinate, $1 \mathrm{mg}$ sorbitol, $250 \mathrm{mg}$ per $\mathrm{ml}$ ) and additional oral osmotic laxatives (lactitol betagalactoside sorbitol, one sachet of $5 \mathrm{~g} / 10 \mathrm{~kg}$ body weight per day divided in two doses). Enemas were given by the parents, preferably for the first three days (if necessary for a maximum of seven days). The last enema was given at least four hours before measurements of sensory threshold, balloon width, and anorectal manometry. Adequate rectal disimpaction was checked by rectal digital examination in all patients.

\section{SENSORY THRESHOLD AND BALLOON WIDTH}

A small catheter (total length $7 \mathrm{~cm}$ ) with two side holes covered by a small standardised balloon was connected to a simple calibrated pressure device. The catheter was connected to a $60 \mathrm{ml}$ syringe, which was used to inflate the balloon. At the paediatric radiology department,

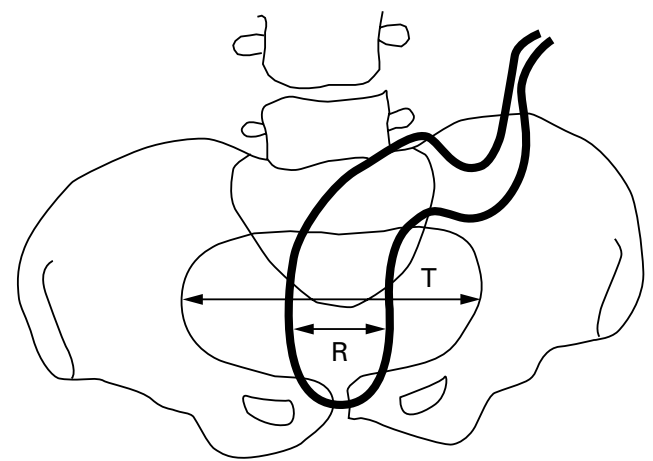

Figure 2 Determination of the RPR. The maximal pelvis diameter (linea transversa) (T) and the rectum diameter $(R)$ at this level are shown. The RPR is calculated by dividing $R$ by T. (Adapted from Meunier et al. ${ }^{5}$ ) 
the catheter and balloon, coated with barium contrast on the outside, were introduced into the rectum with the child in a left lateral position. The balloon was inflated initially with increments of $5 \mathrm{ml}$ air until a volume of $60 \mathrm{ml}$; thereafter with increments of $30 \mathrm{ml}$ until a maximum volume of $300 \mathrm{ml}$ air. The sensory threshold was defined as the smallest reproducible balloon volume sensed by the child. This was the cut off point used to measure balloon width. ${ }^{15}$ Similar to the RPR, a BPR was calculated by dividing the diameter of the balloon by the diameter of the linea transversa of the pelvis. ${ }^{5}$

\section{ANORECTAL MANOMETRY}

Anorectal manometry was performed as described previously. ${ }^{25}$ Maximal anal resting tone was measured by stationary pull through at a rate of $1 \mathrm{~cm}$ per 30 seconds. Maximal squeeze pressure was performed by asking the child to squeeze voluntarily (five to 15 times). The rectal inhibitory reflex was performed by distension of the rectal balloon. The inhibitory reflex was considered to be positive if the anal resting tone decreased with $5 \mathrm{~mm} \mathrm{Hg}$ after distension of the rectal balloon with amounts varying from 5 to $50 \mathrm{ml}$ of air. A positive inhibitory reflex excluded Hirschsprung's disease. Sensory threshold was defined as mentioned above. Critical volume was obtained by filling the intrarectal balloon stepwise with increments of $30 \mathrm{ml}$ air per 30 seconds to a maximum of 300 $\mathrm{ml}$ air. Critical volume was defined as the volume of air required to produce a sensation of persistent urge to defaecate or if abdominal pain was sensed for at least one minute. The defaecation dynamics were defined as normal if the pressure of the external anal sphincter and the integrated electromyogram showed a decrease or no change during an attempt to expel the intrarectal balloon in at least two of five defaecation attempts. Defaecation dynamics were defined as abnormal if a manometric and myoelectrical increase occurred in the sphincter complex during bearing down in at least four of the five defaecation attempts. ${ }^{25} 29$

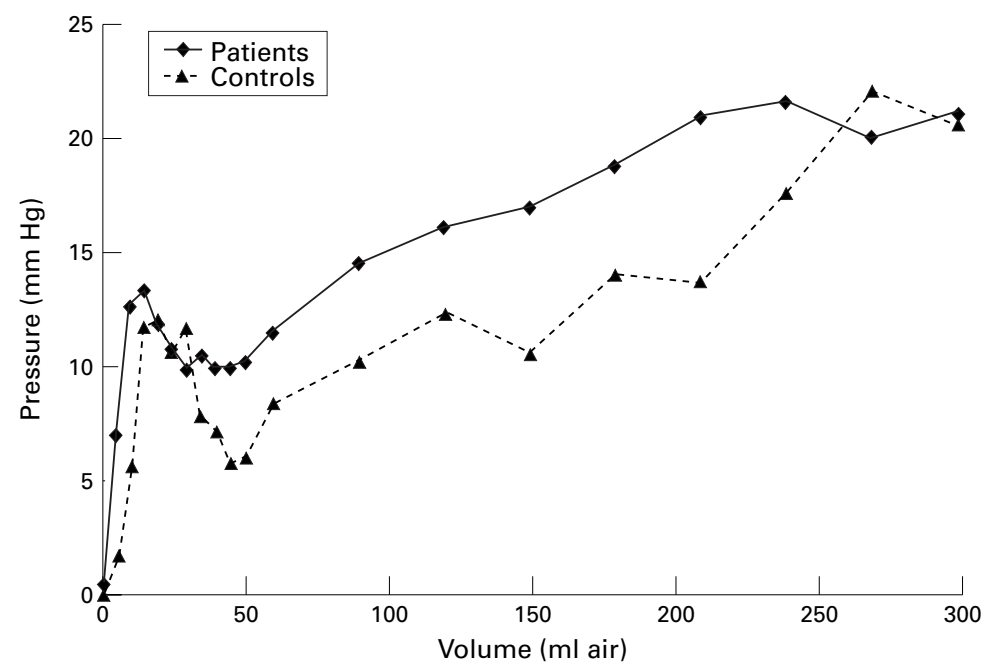

Figure 3 Pressure-volume curve in patients and controls.
RECTOMETROGRAPHY AND RECTAL COMPLIANCE Studies showed that an inflated intrarectal balloon provided a rectal stimulus as well as an intrarectal balloon pressure. ${ }^{63}{ }^{30}$ Balloon pressure was initially increased with increments of $5 \mathrm{ml}$ of air until a volume of $60 \mathrm{ml}$; thereafter with increments of $30 \mathrm{ml}$. Following each increase in volume a latency time of 20 seconds was ensured to allow the rectal wall to adapt. ${ }^{30}$ Inflation of the balloon was continued until the child felt a persistent urge to defaecate, started to complain about abdominal pain, or to a maximum of $300 \mathrm{ml}$ air. Preassessment of the balloon outside the rectum showed that the pressure-volume curve after one inflation up to $300 \mathrm{ml}$ air was not reproducible, whereas the curves were reproducible between the second, third, and fourth time of inflation. Therefore, the balloon was inflated to a maximum of 300 $\mathrm{ml}$ of air twice outside the rectum. After measuring pressures outside the rectum, pressurevolume curves of the rectum were obtained with an intrarectal balloon. To obtain a pressure-volume curve of the rectal wall, the balloon pressures measured outside the rectum were subtracted from the intrarectal balloon pressures. ${ }^{623}$

Compliance of the rectal wall was calculated in patients and controls. Rectometrography was used to determine rectal wall compliance, which was calculated over the range between 50, 90, 120, 150, and $180 \mathrm{ml}$ air, with increments of $30 \mathrm{ml}$. This range was chosen because a gradual increase in pressure was observed only after $50 \mathrm{ml}$ of air inflation. A cut off point of $180 \mathrm{ml}$ air was chosen because many patients and controls complained about abdominal pain above $180 \mathrm{ml}$ air. In contrast to other studies in which rectal compliance was measured at maximal volume, ${ }^{6}$ we calculated the median rectal wall compliance by volume intervals. In this study, rectal wall compliance was calculated by means of a linear regression line - that is, dividing the change in rectal pressure by the change in rectal volume, expressed in $\Delta \mathrm{mm} \mathrm{Hg} / \Delta \mathrm{ml}$ over a range of 50 to $180 \mathrm{ml}$ air inflation (fig 3).

\section{ANALYSIS}

Symptoms, colonic transit times, anorectal manometry, and rectal compliance were expressed in median values and ranges. Differences between groups were calculated using Wilcoxon rank sum analysis for continuous variables and Fisher's exact tests for categorical variables (for example, normal defaecation dynamics). Probability values less than 0.05 indicated a significant difference. The relation between pressure in the rectum $(\mathrm{P})$ and rectal distending volume $(\mathrm{V})$ was examined using a standard linear regression analysis.

The Wilcoxon rank sum test was used to evaluate rectal compliance in patients and controls. Spearman correlation coefficients were calculated to evaluate correlation between clinical parameters and rectal wall compliance.

\section{Results}

Over a period of 12 months, a total of 31 patients ( 22 boys, nine girls) fulfilled the inclu- 
Table 1 Patient characteristics

\begin{tabular}{|c|c|c|}
\hline & $\begin{array}{l}\text { Patient group } \\
(n=32)\end{array}$ & $\begin{array}{l}\text { Control group } \\
(n=6)\end{array}$ \\
\hline Age (y) & $(4-15)$ & $(6-13)$ \\
\hline Boys & 22 & 2 \\
\hline Defaecation/week & $1.00(0-14)$ & $4.25(3-10)$ \\
\hline Soiling/week & $6.00(0-35)$ & $0.75(0-1.5)$ \\
\hline Encopresis/week & $7.5(0-37)$ & $0 \quad(0)$ \\
\hline Night-time soiling & $17 \quad(55 \%)$ & $(0 \%)$ \\
\hline Painful defaecation & $14 \quad(45 \%)$ & $(50 \%)$ \\
\hline Straining & $(55 \%)$ & $(33 \%)$ \\
\hline Abdominal pain & $21 \quad(68 \%)$ & $(100 \%)$ \\
\hline Poor appetite & $16 \quad(52 \%)$ & $(67 \%)$ \\
\hline Enuresis & $(23 \%)$ & $(0 \%)$ \\
\hline Rectal sensation & $(84 \%)$ & $(83 \%)$ \\
\hline Abdominal scybala & $(42 \%)$ & $(17 \%)$ \\
\hline Rectal scybala & $(100 \%)$ & $(0 \%)$ \\
\hline
\end{tabular}

Results expressed as median (range) or number (\%).

sion criteria and in addition, six controls were included in the study. The age of the patients ranged from 4 to 15 years. Children in the control group were aged 6 to 13 years and comprised two boys and four girls.

Table 1 gives patient characteristics. The mean duration of complaints in the patient group was 4.2 years before they were included in the study. A total of $84 \%$ of patients had received laxative treatment for more than one year and psychological treatment had already been given to $34 \%$ of patients. All patients had infrequent bowel movements with regular episodes of soiling or encopresis. Night-time soiling occurred in $55 \%$ of the patients, $23 \%$ had diurnal enuresis, and $42 \%$ had nocturnal enuresis. The control group had a high incidence of painful defaecation (50\%) and straining $(30 \%)$. Colonic transit time measurements were obtained in 27 patients. Four patients did not strictly follow the instructions, resulting in unreliable colonic transit times; they were not included in the analysis. The median segmental transit time was 19 hours (range 2-106), 22.5 hours (3-94), and 84.5 hours (1-178) for the right colon, left colon, and rectosigmoid, respectively. The total colonic transit time was 152 hours (28-216).

Anorectal manometry was obtained in all patients and controls; table 2 shows the results. The results of the anorectal manometry in patients and controls showed no significant differences. Interestingly, the median maximal resting pressure and critical volume in patients was lower compared to controls (53 v $59 \mathrm{~mm}$ $\mathrm{Hg}$ and 150 v $195 \mathrm{ml}$ air, respectively). The prevalence of normal defaecation dynamics (relaxation of the external anal sphincter and increasing the abdominal pressure during an attempt to defaecate), was lower in patients but not significantly, possibly because of the fact that the number of controls was limited.

Table 2 Anorectal manometry in patients and controls

\begin{tabular}{lccl}
\hline Manometry & Patients $(n=31)$ & Controls $(n=6)$ & p value \\
\hline Maximal resting tone (mm Hg) & $52.0(29-81)$ & $59.0(44-88)$ & $0.31^{\star}$ \\
Maximal squeeze pressure (mm Hg) & $130.0(0-331)$ & $154.0(82-271)$ & $0.28^{\star}$ \\
Sensory threshold (ml air) & $20.0(5-300)$ & $22.5(10-40)$ & $0.88^{\star}$ \\
Critical volume (ml air) & $150.0(60-300)$ & $195.0(90-240)$ & $0.59^{\star}$ \\
Normal defaecation dynamics & $11(35 \%)$ & $4(67 \%)$ & $0.21 \dagger$ \\
\hline
\end{tabular}

Results expressed as median (range).

${ }^{\star}$ Calculated using Wilcoxon rank sum analysis.

†Calculated using Fisher's exact test.
The rectal width, defined by the RPR, was obtained in all patients. The mean RPR in patients was 0.68 (range $0.32-0.83$ ). The mean intrarectal balloon width (BPR) was obtained in 25 patients and five controls and the results (0.64 (range 0.37-0.75) and 0.52 (range 0.31$0.61)$ ) were not significantly different. Five patients were excluded from the analysis as two had no empty rectum and three did not cooperate with the investigation. The correlation coefficient between the RPR and BPR in the patient group was $0.15(-0.26<r<0.52)$.

A pressure-volume curve was obtained in 26 patients and six controls. The profile of the curve, as depicted in fig 3, showed a rapid increase of rectal pressure during the first $50 \mathrm{ml}$ of air inflation, followed by a sudden drop in pressure and a subsequent slow increase of pressure after inflation increments above $60 \mathrm{ml}$ air. There was a statistically significant difference between patients and controls for the pressure at a balloon volume of $50 \mathrm{ml}$ $(p=0.013)$. Further balloon volume increase resulted in a slow gradual increase in pressure. Interestingly, the pressure-volume curve of patients showed a tendency to higher pressures compared to that of controls (fig 3). However, this difference was not statistically significant.

The median rectal wall compliance calculated from the obtained pressure-volume curves of patients was $0.07(\Delta \mathrm{mm} \mathrm{Hg} / \Delta \mathrm{ml})$ compared to $0.06(\Delta \mathrm{mm} \mathrm{Hg} / \Delta \mathrm{ml})$ in controls. This difference was not significant $(p=0.98)$. Figure 4 shows that the slope of the regression line was comparable between patients and controls.

Furthermore, no correlations were found between manometric parameters (critical volume, sensory threshold) and rectal compliance (data not shown). The RPR and the BPR, as measured with abdominal radiographs, did not correlate with rectal wall compliance (data not shown).

\section{Discussion}

The term megarectum is often used indiscriminately in patients with constipation or faecal impaction but often lacks quantitative measures. However, faecal impaction is not a diagnosis and it is therefore more appropriate to describe faecal impaction rather than suggesting an underlying mechanism. ${ }^{5}$ In children with constipation it is important to recognise and accurately describe clinical features in order to determine the severity of constipation and to initiate an appropriate treatment strategy. In a recent chapter about megarectum in children, the major symptoms are described but no clear definition or measure for megarectum was provided. ${ }^{31}$ Therefore, we conducted a controlled study in chronically constipated children with rectal faecal impaction on digital rectal examination and a group of children with an empty rectum on digital examination. All children underwent radiological investigations and anorectal manometry. A pressure-volume curve was performed to obtain objective measures about rectal function.

Many patients had long histories of defaecation problems with faecal soiling and/or encopresis despite laxative or psychological 

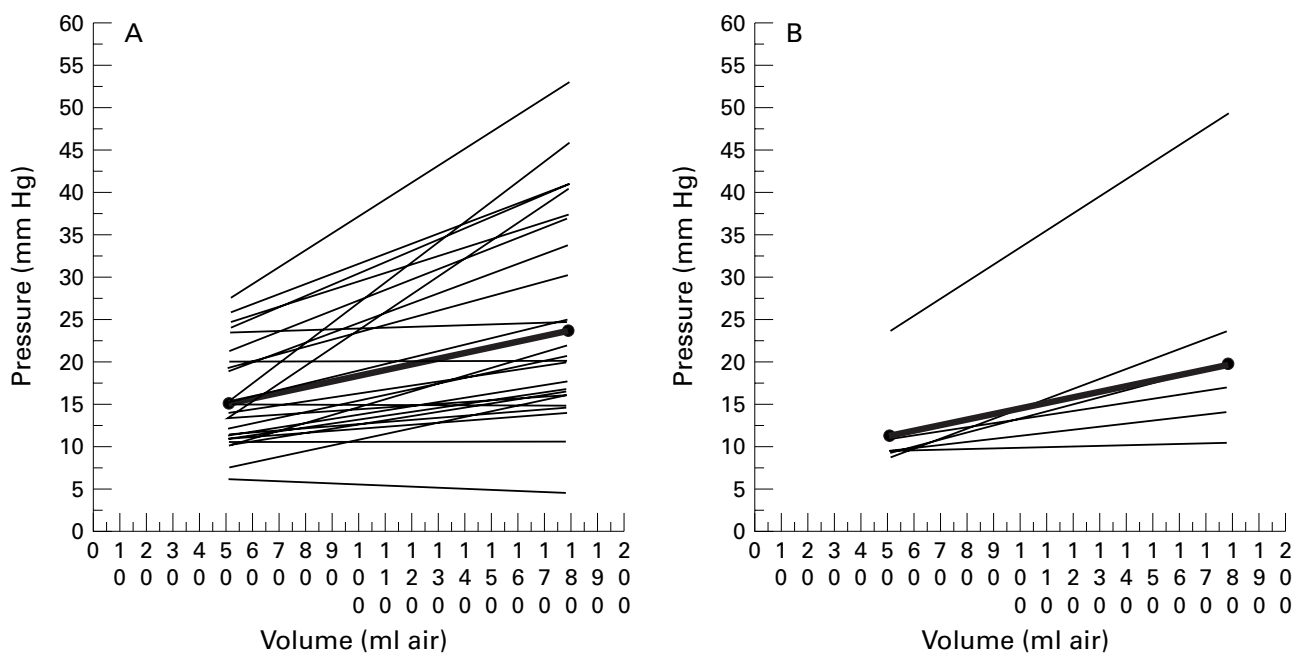

Figure 4 Regression lines of the patients $(A)$ and controls (B). The grey lines represent the lines of individuals and the thick black line represents the average in the groups. The slope of the regression line is comparable for patients and controls.

treatment. The rectosigmoid and total colonic transit times of patients were prolonged compared to the only available control group, as described by Arhan et al. ${ }^{28}$ However, no significant anorectal abnormalities were found between the patient and control group on anorectal manometry. The pressure-volume curves between patients and controls were comparable, but tended to show higher rectal pressures in patients. The rectal compliance, defined by the slope of the regression line of the pressure-volume curve was comparable for patients and controls. Moreover, clinical symptoms, radiological, and/or manometric parameters were not associated with the rectal compliance. With this study, we have not been able to define megarectum in children by radiological and anorectal manometrical investigations.

Faecal incontinence in children with constipation - that is, soiling or encopresis, is an embarrassing complaint, and often the reason for parents to seek medical advice. Soiling is often explained by a diminished sensory threshold and subsequent accumulation of faeces followed by the loss of faecal material in their underwear. ${ }^{615}$ The high incidence of night-time soiling and enuresis in this study confirms earlier findings in children with severe constipation. ${ }^{24}$ The relatively high incidence of painful defaecation, straining, and abdominal pain in the control group may suggest that these children suffer from irritable bowel syndrome. ${ }^{32}$ We are aware that this may have influenced the results of the anorectal manometry and rectometrography, ${ }^{33}$ but, because of ethical considerations no other control group was eligible for rectal investigation.

The colonic transit time measurement using radio-opaque markers is an objective method to obtain information about the function of the entire colon. In accordance with others, an important delay in the rectosigmoid colon was found in most constipated children. ${ }^{74} 35$ The median transit time of the proximal colon was within normal limits. ${ }^{28}$ The rectosigmoid and total colonic transit times were extremely delayed and exceeded the upper limit of normal controls as described by Arhan et $a .^{28}$ This observation suggests that in constipated children with an enlarged rectum, the function of the proximal colon is relatively normal up to the rectosigmoid and a dysfunction in the rectosigmoid might be responsible for the delay in the total colonic transit time. ${ }^{6736}$ It is still unclear whether the rectosigmoid dysfunction is caused by motor or by sensory abnormalities of the rectum. ${ }^{37-39}$

With anorectal manometry no significant differences were found between the patient and control groups. This was also found in earlier studies in children with constipation. ${ }^{25}{ }^{29}$ Other studies have described higher maximal tolerable volumes, ${ }^{5}$ diminished rectal sensation, ${ }^{5} 15373840$ and higher rectal capacities ${ }^{25} 23$ in patients with faecal impaction compared to controls. They have suggested that these abnormalities were responsible for the enlargement of the rectum. However, in this study the sensory threshold was comparable between patients and controls. The lower (albeit not significantly) prevalence of normal defaecation dynamics in our patients compared with controls is in accordance with previous studies. ${ }^{25} 29$

There is still controversy about the use of an abdominal $x$ ray examination in the work up of children with constipation. An abdominal $x$ ray examination seems to have little value because of the large overlap with healthy controls..$^{5-7} 41$ However, in adults, measurement of the rectal diameter in the lateral view on an $x$ ray picture is found to be reliable. Many investigators use this method, with a cut off point of $6.5 \mathrm{~cm}$, to define an abnormal enlargement of the rectum. ${ }^{13}{ }^{19}$ The obtained RPR in our patients with faecal impaction of this study was 0.68 . We were not able to compare this observation with the control group as all controls were selected on the basis of an empty rectum. We felt it unethical to perform repeated radiological investigations in order to obtain a RPR of an empty rectum and colonic transit times. Therefore, we can only compare this result to a previous study in children, showing a large difference between the RPR of patients and controls, namely 0.79 and 0.47 , respectively. ${ }^{5}$ 
However, no cut off values were suggested. After disimpaction the intrarectal balloon width, measured at first rectal sensation, was 0.64 in patients and 0.52 in controls, with an upper limit value of 0.61 in the control group. The initial rectal sensation is much easier to study than the urge to defaecate and results vary little among different studies. ${ }^{15}$ Some have suggested that this upper limit value can be taken as a cut off point. ${ }^{13}$ If we take 0.61 as a cut off point, it shows that only a selection of patients has an abnormal balloon pelvic ratio. The results of the RPR and the BPR in the patient group showed no correlation (correlation coefficient 0.15 ). This may be explained by the fact that balloon width was obtained at sensory threshold, whereas the rectal width was obtained during rectal impaction. This explanation also implies that a large rectal capacity (faecal impaction) is not the result of a lack of rectal sensation; this is in contrast with other studies in adults and children. ${ }^{15}{ }^{42}$ Although an abdominal $x$ ray examination is not adequate to diagnose and treat constipation in children, it seems appropriate to perform this radiological investigation in children who have failed initial laxative treatment, primarily to calculate their RPR. On the basis of this study we suggest that an RPR above 0.61 , being the upper limit of controls, defines an enlarged rectum and is an appropriate cut off point to select children for further anorectal investigations in order to evaluate a possible megarectum. ${ }^{13}{ }^{15}$

One of the additional investigations in patients with an enlarged rectum is the determination of a pressure-volume curve of the rectum (rectometrogram). This investigation provides valuable information on rectal wall functioning. ${ }^{5}$ The profile of the pressurevolume curve in this study showed a rapid reduction of pressure at $50 \mathrm{ml}$ of air inflation; this has not been described by others. ${ }^{37}$ The initial increase in rectal pressure most likely corresponds with the rectorectal reflex threshold - that is, contraction of the rectum in response to distension, as described by Meunier et $a .^{5}$ The decrease in rectal pressure probably corresponds to the adaptation of the rectum at sensory threshold. ${ }^{23}{ }^{30}$ Interestingly, the pressure decrease in patients was less, resulting in a significantly higher pressure at a volume of $50 \mathrm{ml}$ air compared to controls. This difference may be explained by a diminished degree of relaxation and adaptation of the chronically enlarged rectum of the patients. In contrast to many other studies further distension resulted in a tendency to higher rectal pressures in the patient group compared to the control group. ${ }^{6}{ }^{14}{ }^{37}$ However, there was no significant difference between patients and controls; this was primarily because of large variations in rectal pressures in both groups.

We explain this lack of relaxation by the development of myohypertrophy as a potential adaptation mechanism in the constipated child, which is probably lost in adults with chronic faecal impaction. ${ }^{31}{ }^{43}$ This hypothesis corresponds with previous studies, describing similar findings at surgery or at autopsy in constipated children. ${ }^{43}{ }^{44}$ Moreover, the hypothesis conforms with Laplace's law: the tension in the wall at a given pressure is proportional to the radius of the cylinder. ${ }^{3043}$ Thus, in patients with chronic rectal faecal impaction, the rectal wall develops myohypertrophy in an attempt to overcome chronic faecal loading and only after many years, and most likely not during childhood $^{23}$; this compensatory mechanism finally fails and decompensation and distension of the rectal wall occurs, resulting in decreased rectal wall pressures measured in adults. ${ }^{13} 4246$

Many investigators have measured rectal wall compliance at maximal intrarectal balloon volume, ${ }^{5647}$ which provides information about the rectal wall at only one point and reveals nothing about the mechanism. Therefore, we have calculated the rectal wall compliance over several interval volumes. Our method to measure rectal compliance, is in our opinion more appropriate because it provides information about rectal wall function during distension. ${ }^{5}$ Using this method, we showed that the rectal wall compliance was comparable for patients and controls. As fig 4 shows, the slopes of the regression lines between patients and controls were comparable, although the regression line of patients was higher compared to controls. This result is new and seems to contrast with previous studies. $^{5} 144849$

Interestingly, the duration of complaints was not associated with changes in rectal wall compliance. ${ }^{23}{ }^{50}$ Furthermore, manometric and radiological parameters were not correlated with the rectal wall compliance. ${ }^{5}$ Therefore, it is questionable whether rectal wall compliance measurement is a reliable parameter to define megarectum in constipated patients. Recent studies in adults showed the colon and rectum had a decreased contractility which was often present in combination with an enlarged rectum..$^{30}$ It is suggested that impairment of the colonic muscle tone in adult patients correlates with decompensation of the rectal pressures. ${ }^{39}$ Thus, anorectal investigation may be extended with barostat measurement to obtain additional information about rectal wall functioning.

One mechanism for the development of megarectum might be a disorder in rectal sensation, resulting in faecal loading and subsequent enlargement of the rectum with finally impairment of the rectal wall properties. This hypothesis is supported by a study by LoeningBaucke who showed a defect in the afferent pathway from the rectum in children with constipation and encopresis. ${ }^{37} 38$ However, our study did not support this suggestion as we found no significant differences for rectal sensation between patients and controls.

Secondly, a disorder in the viscoelasticity of the rectal wall causes poor rectal functioning and may consequently result in faecal retention. ${ }^{36}{ }^{40}$ This hypothesis is supported by studies that have shown abnormalities with anorectal manometry and rectometrography. ${ }^{5}$ We can support part of this hypothesis as this study also showed less relaxation at $50 \mathrm{ml}$ inflation in patients. However, further distension showed a comparable slope of the pressure-volume curves and rectal wall com- 
pliance between patients and controls. More information could be given by barostat measurement which may be included in future studies on rectal wall functioning.

Finally, an enlarged rectum may be the result of initial psychological problems. ${ }^{15}{ }^{36}{ }^{43}$ Faecal soiling is often considered to be a result of denial of rectal sensation, or laziness or disobedience by the child. ${ }^{36}{ }^{45}$ This suggestion may result in coercive toilet training by parents and subsequently anxiety by the child and sometimes painful defaecation. ${ }^{43}$ The child may start to postpone defaecation, causing faecal impaction and enlargement of the rectum. ${ }^{4451}$

In conclusion, the term faecal impaction should be used in children with a filled rectum on digital rectal examination. An abdominal $x$ ray examination can be performed to identify an enlarged rectum, which we propose to define by a RPR of 0.61 or larger. When rectal width is above 0.61 , which is the upper limit of normal controls in this study, additional evaluation of rectal wall functioning (anorectal manometry and pressure-volume curves) is advised in order to exclude rectal wall abnormalities and the presence of a megarectum.

We propose to use only the term megarectum in children when functioning of rectal wall or nerve supply shows abnormalities on appropriate investigations. The question remains as to whether very long duration of faecal impaction finally results in megarectum. Most importantly, given the often still normal functioning of the rectal wall, it is essential to treat children vigorously (oral laxatives, preferably in combination with enemas) when they have chronic constipation, faecal impaction, or an enlarged rectum.

1 Read NW, Timms JM. Pathophysiology of constipation. Acta Gastroenterol Belg 1987;50:393-404.

2 Clayden GS. Management of chronic constipation. Arch Dis Child 1992;67:340-4

3 Schnaufer L, Mahesh Kumar AP, White JJ. Differentiation and management of incontinence and constipation problems in children. Surg Clin North Am 1970;50:895-905.

4 Leon SH, Krishnamurthy S, Schuffler MD. Subtotal colectomy for severe idiopathic constipation. A follow-up study tomy for severe idiopathic constipation. A fo

5 Meunier P, Louis D, Jaubert de Beaujeu M. Physiologic investigation of primary chronic constipation in children: comparison with the barium enema study. Gastroenterology 1984;87:1351-7.

6 Verduron A, Devroede G, Bouchoucha M, et al. Megarectum. Dig Dis Sci 1988;33:1164-74.

7 Benninga MA, Büller HA, Staalman CR, et al. Defaecation disorders in children, colonic transit time versus the Barr-score. Eur f Pediatr 1995;154:277-84.

8 Benninga MA, Büller HA, Heymans HS, Tytgat GN, Taminiau JA. Is encopresis always the result of constipation? Arch Dis Child 1994;71:186-93.

9 Liebman WM. Disorders of defecation in children: evaluation and management. Postgrad Med 1979;66:105-8.

10 Loening-Baucke VA, Cruikshank BM. Abnormal defecation dynamics in chronically constipated children with encopredynamics in chronically constipat
sis. F Pediatr 1986;108:562-6.

11 Loening-Baucke VA. Factors responsible for persistence of childhood constipation. $\mathcal{F}$ Pediatr Gastroenterol Nutr 1987;6: 915-22.

12 Staiano A, Andreotti MR, Greco L, Basile P, Auricchio S. Long-term follow-up of children with chronic idiopathic constipation. Dig Dis Sci 1994;39:561-4.

13 Preston DM, Lennard-Jones JE, Thomas BM. Towards a radiologic definition of idiopathic megacolon. Gastrointest Radiol 1985;10:167-9.

14 Suzuki H, Amano S, Honzumi M, Saijo H, Sakakura K. Rectoanal pressures and rectal compliance in constipated infants and children. Z Kinderchir Grenzgeb 1980;29:330-6.

15 Meunier P, Mollard P, Marechal JM. Physiopathology of megarectum: the association of megarectum with encopremis. Gut 1976;17:224-7.

16 Partin JC, Hamill SK, Fischel JE, Partin JS. Painful defecation and fecal soiling in children. Pediatrics 1992;89: 1007-9.
17 Stabile G, Kamm MA, Phillips RK, Hawley PR, LennardJones JE. Partial colectomy and coloanal anastomosis for idiopathic megarectum and megacolon. Dis Colon Rectum 1992:35:158-62.

18 Stabile G, Kamm MA, Hawley PR, Lennard-Jones JE. Results of the Duhamel operation in the treatment of idiopathic megarectum and megacolon. Br F Surg 1991;78: 661-3.

19 Stabile G, Kamm MA, Hawley PR, Lennard-Jones JE. Colectomy for idiopathic megarectum and megacolon. Gut 1991;32:1538-40.

20 Fleisher DR. Diagnosis and treatment of disorders of defecation in children. Pediatr Ann 1976;5:700-22.

21 Rappaport LA, Levine MD. The prevention of constipation and encopresis: a developmental model and approach. Pediatr Clin North Am 1986;33:859-69.

22 Preston DM, Lennard-Jones JE. Anismus in chronic constipation. Dig Dis Sci 1985;30:413-18.

23 Callaghan RP, Nixon HH. Megarectum: physiological observations. Arch Dis Child 1964;39:153-7.

24 Benninga MA, Büller HA, Tytgat GNJ, Akkermans LMA, Bossuyt PM, Taminiau JAJM. Colonic transit time in constipated children: does pediatric slow-transit constipation exist? F Pediatr Gastroenterol Nutr 1996;23:241-51.

25 Plas van der RN, Benninga MA, Büller HA, et al. Biofeedback training in treatment of childhood constipation: a randomised controlled study. Lancet 1996; 348:776-80

26 Apley J, Naish N. Recurrent abdominal pain: a field survey of 1,000 school children. Arch Dis Child 1958;33:165-70.

27 Metcalf AM, Phillips SF, Zinsmeister AR, MacCarty RI Beart RW, Wolff BG. Simplified assessment of segmental colonic transit. Gastroenterology 1987;92:40-7.

28 Arhan P, Devroede G, Jehannin B, et al. Segmental colonic transit time. Dis Colon Rectum 1981;24:625-9.

29 Benninga MA, Büller HA, Taminiau JA. Biofeedback training in chronic constipation. Arch Dis Child 1993;68:126-9.

30 Bouchoucha M, Denis P, Arhan P, et al. Morphology and rheology of the rectum in patients with chronic idiopathic constipation. Dis Colon Rectum 1989:32:788-92.

31 JE Lennard-Jones. Clinical features of idiopatic megarectum and megacolon in adults. In: Kamm ME, Lennard-Jones JE, editors. Constipation. Wrightson Biomedical Publishing Ltd, 1994:225-31

32 Hyams JS, Treem WR, Justinich CJ, Davis P, Shoup M, Burke G. Characterization of symptoms in children with recurrent abdominal pain: resemblance to irritable bowel syndrome. F Pediatr Gastroenterol Nutr 1995;20:209-14.

33 Prior A, Maxton DG, Whorwell PJ. Anorectal manometry in irritable bowel syndrome: differences between diarrhoea and constipation predominant subjects. Gut 1990;31:45862.

34 Corazziari E, Cucchiara S, Staiano A, et al. Gastrointestinal transit time, frequency of defecation, and anorectal manometry in healthy and constipated children. 7 Pediatr 1985;106:379-82.

35 Vattimo A, Burroni L, Bertelli P, Messina M, Meucci D, Tota G. Total and segmental colon transit time in constipated children assessed by scintigraphy with $111 \mathrm{In}$ DTPA given orally. F Nucl Biol Med 1993;37:218-22.

36 Oppe TE. Megacolon and megarectum in older children. Proc R Soc Med 1967;60:803-5.

37 Loening-Baucke VA. Sensitivity of the sigmoid colon and rectum in children treated for chronic constipation. $\mathcal{F}$ Pediatr Gastroenterol Nutr 1984;3:454-9.

38 Loening-Baucke V, Yamada T. Is the afferent pathway from the rectum impaired in children with chronic constipation and encopresis? Gastroenterology 1995;109:397-403.

39 von der Ohe MR, Camilleri M, Carryer PW. A patient with localized megacolon and intractable constipation: evidence for impairment of colonic muscle tone. Am $\mathcal{7}$ Gastroenterol 1994;89:1867-70.

40 Molnar D, Taitz LS, Urwin OM, Wales JK. Anorectal manometry results in defecation disorders. Arch Dis Child 1983;58:257-61

41 Patriquin H, Martelli H, Devroede G. Barium enema in chronic constipation: is it meaningful? Gastroenterology 1978;75:619-22

42 Lane RH, Todd IP. Idiopathic megacolon: a review of 42 cases. Br F Surg 1977;64:307-10.

43 Nixon HH. Megarectum in the older child. Proc R Soc Med 1967;60:801-3.

44 Clayden GS, Lawson JO. Investigation and management of long-standing chronic constipation in childhood. Arch Dis Child 1976;51:918-23.

45 Clayden G, Agnarsson U. Constipation in childhood. New York: Oxford University Press, 1991:1-92.

46 Preston DM, Lennard-Jones JE. Pelvic motility and response to intraluminal bisacodyl in slow-transit constipaion. Dig Dis Sci 1985;30:289-94.

47 Meunier PD, Gallavardin D. Anorectal manometry: the state of the art. Dig Dis 1993;11:252-64

48 Cucchiara S, Coremans G, Staiano A, et al. Gastrointestinal transit time and anorectal manometry in children with fecal soiling. F Pediatr Gastroenterol Nutr 1984;3:545-50.

49 Alstrup NI, Rasmussen OO, Christiansen J. Effect of rectal dilation in fecal incontinence with low rectal compliance. Report of a case. Dis Colon Rectum 1995;38:988-9.

50 Barnes PR, Lennard-Jones JE, Hawley PR, Todd IP. Hirschsprung's disease and idiopathic megacolon in adults and adolescents. Gut 1986;27:534-41.

51 Ehrenpreis T. Megacolon and megarectum in older children and young adults. Classification and terminology. Proc $R$ Soc Med 1967;60:799-801. 